\title{
$8 q 12$ microduplication including CHD7: clinical report on a new patient with Duane retraction syndrome type 3
}

Anna Baroncini ${ }^{1}$, Sara Bertuzzo ${ }^{2}$, Rita Quarantini ${ }^{3}$, Paolo Ricciardelli ${ }^{4}$, Roberto Giorda ${ }^{5}$ and Maria Clara Bonaglia $2^{*}$

\begin{abstract}
Background: A novel multiple congenital anomalies syndrome has been recently identified in four patients carrying a 8q12 microduplication sharing the smallest region of overlap ( $\mathrm{SRO}$, size 1.6 Mb) including five genes $C A 8$, $A S P H, R A B 2 B, C L V S 1$ and CDH7. The phenotype is mainly characterized by neurodevelopmental delay, heart defects, facial features and Type 1 Duane anomaly. Increasing dosage of $\mathrm{CDH} 7$ was proposed to be responsible for the recurrent pattern of MCA.

Results: High resolution array-CGH analysis identified a 4.2 Mb de novo interstitial duplication of the 8q12.1-q12.3 chromosome region in a boy with developmental delay, dysmorphic features, type 3 Duane anomaly. This duplication includes several genes and spans the SRO.

Discussion: The present case represents a further patient with an interstitial duplication of chromosome 8q12 and several shared clinical features. Although more cases are needed to delineate the full-blown phenotype of $8 q 12$ duplication syndrome, published data and present observations suggest that it results in a clinically recognizable phenotype. The presence of Duane anomaly in four out of five described patients with a $8 q 12$ duplication definitely rules against the possibility of its being a chance finding unrelated to the imbalance and points toward a pathogenic role. Gene content analysis of the duplicated region and review of the literature suggest that gain-of-dosage of the CHD7 gene may be a good candidate for the main clinical features of the syndrome.
\end{abstract}

Keywords: $8 \mathrm{q} 12$ microduplication, Array-CGH, CHD7, Duane retraction syndrome

\section{Background}

Microduplication of 8q12, encompassing the CHD7 gene, which is mutated or deleted in CHARGE syndrome, has recently been identified to result in a novel multiple congenital anomalies syndrome. Hitherto four patients have been described, with duplication sizes ranging from 2.7 to $6.9 \mathrm{Mb}$ and different breakpoints within the 8q12 region [1-4]. The phenotype, though variable, is mainly characterized by neurodevelopmental delay, heart defects, and facial features. Type 1 Duane anomaly has been reported in three out of the four described cases, the exception being the child with the smaller duplication. Duane retraction syndrome (DRS) is a highly heterogeneous eye-movement disorder that in a quarter to half of cases is associated with

\footnotetext{
* Correspondence: clara.bonaglia@bp.Inf.it

${ }^{2}$ Cytogenetics Laboratory, Scientific Institute, IRCCS Eugenio Medea, Bosisio

Parini, Via Don Luigi Monza, 20, 23842 Bosisio Parini(LC), Italy

Full list of author information is available at the end of the article
}

additional congenital defects and/or genetic syndromes [5]. Beyond the present microduplication, involvement of chromosome 8 with Duane anomaly has been documented in mosaic trisomy 8 [6,7], in $8 \mathrm{q} 13$ deletions $[8,9]$, and in a de novo reciprocal balanced translocation disrupting the CPA6 gene in 8q13 where the Duane retraction syndrome 1 locus (DURS1) is located [10].

Here we report on a further child who carries a de novo 4.2 Mb duplication of the region 8q12.1-q12.3 presenting with developmental delay, dysmorphic features, and type 3 Duane anomaly in order to refine the clinical presentation of the 8q12 microduplication syndrome and to contribute to genotype-phenotype correlation.

\section{Case presentation}

The child was referred to our Clinical Genetics Service for dysmorphic features and developmental delay. The patient was the third child of healthy unrelated parents 
with uneventful family history. He was born at 39 weeks of gestation, after a normal pregnancy, with urgent caesarean section due to placental abruption. No intrauterine exposure to drugs and other possibly harmful factors were reported. At birth, weight was $2570 \mathrm{gr}$, length $47 \mathrm{~cm}$, head circumference $32 \mathrm{~cm}$, and thoracic circumference $33 \mathrm{~cm}$. APGAR scores were $9 / 10$ at $1^{\prime} / 5^{\prime}$, respectively. At cardiological evaluation, a $2 / 6$ systolic ejection murmur was detected and an echocardiogram showed a patent foramen ovale with left-to-right shunt, which spontaneously disappeared within six months of life. Developmental delay and muscle hypotonia were observed since the first months of life.

On first examination at the Genetic Clinic, at age 16 months, he was $82 \mathrm{~cm}$ tall $\left(75^{\text {th }}\right.$ centile), weighed $11.3 \mathrm{Kg}\left(50^{\text {th }}\right.$ centile) and his head circumference was $45.2 \mathrm{~cm}\left(<3^{\text {rd }}\right.$ centile). He had brachycephaly (cephalic index: 87\%), full cheeks, medial flaring of eyebrows, long eyelashes, epicanthic folds, strabismus, normal ears with total length of $4.7 \mathrm{~cm}\left(50^{\text {th }}\right.$ centile), short nose, low and widened nasal root, long philtrum, full lower lip, tooth enamel erosions. Chest circumference was $52 \mathrm{~cm}\left(75^{\text {th }}\right.$ percentile) and the internipple distance was $13 \mathrm{~cm}\left(97^{\text {th }}\right.$ percentile). Hands had normal length $\left(50^{\text {th }}-75^{\text {th }}\right.$ percentile), tapering fingers and low set thumbs. Feet length was $13 \mathrm{~cm}\left(75^{\text {th }}\right.$ percentile) (Figure $\left.1 \mathrm{~B}\right)$.

At age 28 months, stature and weight were respectively at $97^{\text {th }}$ and $75^{\text {th }}$ percentile while head circumference was still $<3^{\text {rd }}$ percentile.

Motor skills were significantly delayed: he was able to sit unassisted and to stand up without support since age
24 and 38 months, respectively, and began walking with assistance since age 45 months. Language delay was significant: at age 3 years and 9 months he vocalized but didn't yet use any word to communicate. At the same age he had not yet achieved toilet training and head, trunk and hand stereotypies, noted since the first year of life, were still present though less common. Constipation and feeding problems, mainly consisting in long feeding times, difficulty chewing and fluids dysphagia, have been moderately ameliorating over the years.

A MRI of the brain, at age 7 months, showed no abnormalities except for a thin corpus callosum. Abdominal ultrasound was normal. Ear, nose and throat examination didn't disclose anomalies and brainstem auditory evoked potentials were within normal limits. Ophthalmological evaluation, at age 3 years, detected anisocoria $(R>L)$, slight inconstant nystagmus and exotropia in primary position of the left eye; fundoscopy was normal. Examination of the ocular motor system revealed in the left eye restricted abduction and absent adduction with globe retraction and palpebral fissure narrowing at attempted adduction and concluded for a unilateral type 3 Duane syndrome. Conventional cytogenetic studies showed a normal karyotype $(46, \mathrm{XY})$.

\section{Results}

In the absence of any etiological diagnosis, array CGH analysis using the $180 \mathrm{~K}$ array platform was performed in the patient detecting a 8q12.1q12.3 duplication of 4.2 $\mathrm{Mb}$, as described in Figure 1A. Quantitative PCR performed on the patient and his parents evidenced that

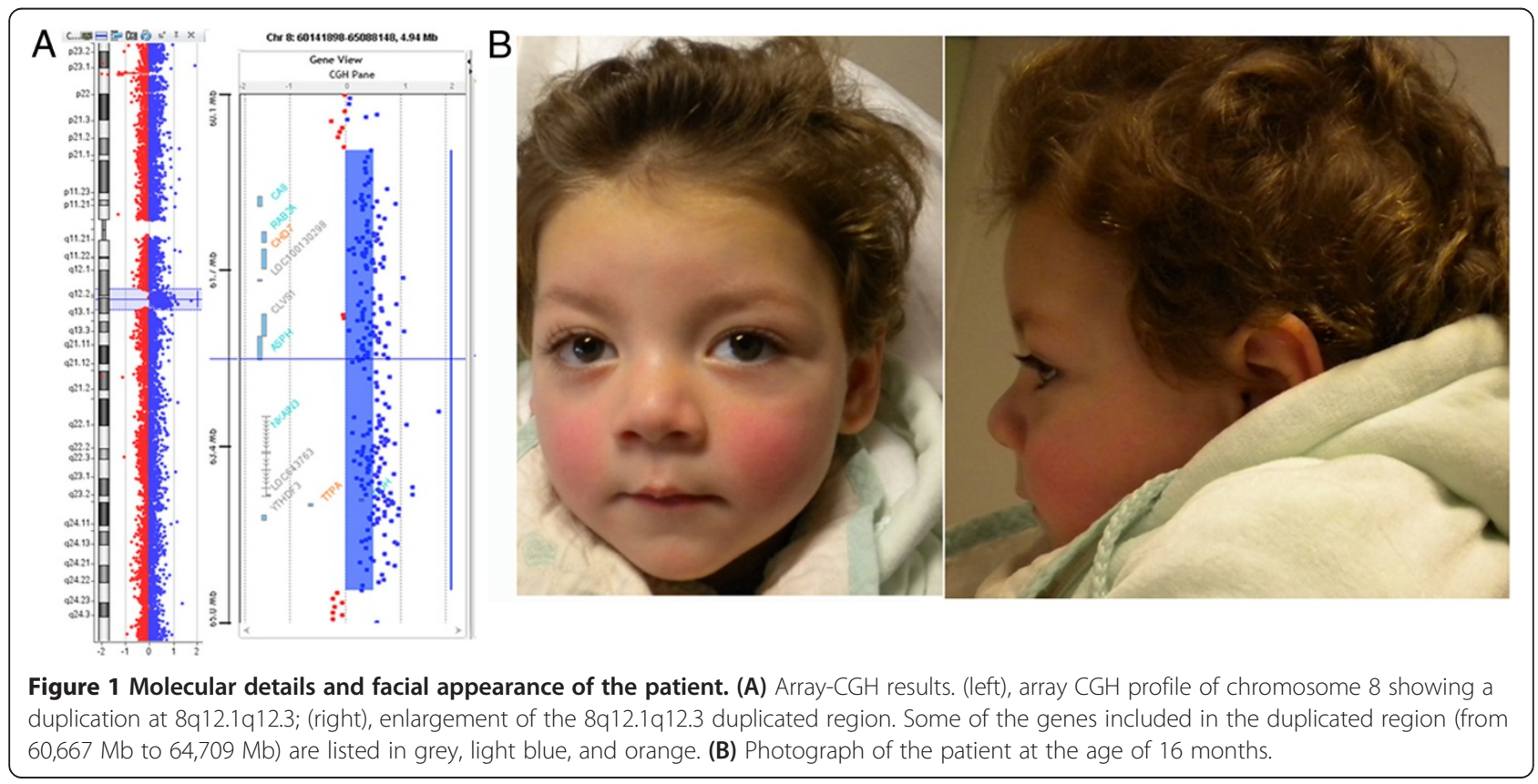


the $8 \mathrm{q} 12.1 \mathrm{q} 12.3$ duplication originated de novo, while genotyping of polymorphic loci demonstrated the paternal origin of the duplication (data not shown).

FISH analysis on metaphases from both proband's parents excluded the presence of insertional translocations of 8q12.1q12.3 (data not shown). The final interpretation of the rearrangement was arr[hg19] 8q12.1q12.3(60,637, $619 \times 2,60,667,866-64,709,770 \times 3,64,734,723 \times 2) \mathrm{dn}$.

\section{Discussion}

With this case, five patients with partially overlapping 8q12 microduplications have been described, sharing common features the most consistent of which, observed in at least four subjects, are neonatal hypotonia, developmental delay, facial features, heart defects, and Duane anomaly. A similar facial gestalt is noticed, with full cheeks or round face, flared medial eyebrows, short nose with widened root, long philtrum, full lower lip. Hearing loss, urinary malformations, and microbrachycephaly appear inconstant findings, while variable behavioural anomalies, feeding problems and constipation are present in the majority of cases. The smallest region of overlap (SRO) between the published cases, including the present one, is around $1.6 \mathrm{Mb}$ and spans five genes: $C A 8, A S P H, R A B 2 B$, $C L V S 1$, and $C D H 7$. Up to now, only two of these genes, CHD7 and CA8, have been linked to a human disease. CHD7 haploinsufficiency, either by mutation or deletion, is causative of the CHARGE syndrome. Homozygous mutation in the CA8 gene, encoding carbonic anhydrase VIII, has recently been found in Congenital ataxia with predisposition to quadrupedal gait (OMIM \#613227) [11].

The reported association of $8 \mathrm{q} 12$ microduplication and DRS suggests a possible causal involvement of the dosagesensitive $C H D 7$ gene [1-3].

In fact, in all patients the $C H D 7$ gene is included in the duplicated region but none of them has the distinctive face nor fulfils the clinical criteria for typical or partial/ incomplete Charge syndrome according to Verloes' categorization [12] and only in the child described by Monfort et al. [1] a major sign of the syndrome, represented by a Mondini anomaly, was observed. Therefore, CHD7 copy number increase doesn't appear a likely pathogenic mechanism underlying Charge's aetiology.

Duane retraction syndrome (DRS) is a congenital ocular motility disorder resulting in absent or marked restriction of abduction (type 1), adduction (type 2), or both (type 3 ), in addition to globe retraction and palpebral fissure narrowing on attempted adduction, as a result of a congenital anomaly of the 6th cranial nerve nuclei with paradoxical innervation of the lateral rectus from the 3rd cranial nerve. According to pooled data, type 1 is by far the most common (78\%), followed by type $3(15 \%)$ and $2(7 \%)$. Approximately $0,1 \%$ of the general population, without ethnic preferences, and $1-4 \%$ of all strabismus cases show
DRS, with a predilection for unilateral involvement of the left eye and for female patients [13].

Most cases are sporadic but familial transmission, commonly autosomal dominant, has been documented in several instances, usually in relation to isolated Duane anomaly. Beside a number of recognizable syndromes that are monogenic in origin, Duane anomaly has also been observed in a variety of numerical and structural chromosome aberrations involving different chromosomes, locations, and sizes. However, up to now the majority of these reports have been sporadic findings that might represent chance association, whereas contribution of chromosomes 8 and 20 appears to be substantial.

DRS associated with interstitial deletion of the 20q13 region is probably due to haploinsufficiency of the SALL4 gene, causative of the Duane-Radial Ray syndrome (OMIM \#607323).

In addition to the present microduplication, involvement of chromosome 8 with Duane anomaly has been documented in mosaic trisomy 8 [6,7], and in 8q13 deletions $[8,9]$ although the precise localisation of the deletions was not defined, since the paper was published prior to the advent of microarrays.

Furthermore, a de novo balanced translocation disrupting the CPA6 gene, located within the DURS1 locus in $8 \mathrm{q} 13$, was reported in a patient exhibiting features of Duane retraction syndrome [10]. As demonstrated in zebra fish, conserved expression of CPA6 in cartilaginous precursors posterior to the eye strongly suggests a role in the aetiology of Duane anomaly. However, its deficiency alone doesn't affect development or function of the VI nerve in the animal model and may not be enough to cause the ocular motility disorder, requiring interaction with other genes and/or enhancer elements [14]. These data suggest that involvement of the 8q13 locus in Duane anomaly still remains uncertain, while the presence of a Duane anomaly in four out of the five described patients with a 8q12 triplication definitely rules against the possibility of a coincidence unrelated with the overlapping imbalances, as previously considered among the various hypotheses, and points toward a pathogenic role.

\section{Conclusion}

In conclusion, our patient with $8 \mathrm{q} 12$ deletion of $4.2 \mathrm{Mb}$, including the $1.6 \mathrm{Mb} \mathrm{SRO}$, supports the hypothesis that CHD7 might be the most likely candidate for generating the main clinical features of the syndrome and influencing the appearance of Duane anomaly.

\section{Methods \\ Array-CGH analysis}

Array-CGH was performed using the Agilent Human Genome CGH Microarray Kit 180 k (Agilent Technologies 
Inc., Santa Clara, CA) with a resolution of $\sim 40 \mathrm{~Kb}$ (Figure 1A). All nucleotide positions refer to the Human Genome, Feb 2009 Assembly (hg19). Data analysis was performed using Agilent Cytogenomics version 2.5.8.1.

\section{Fish analysis}

FISH was performed on both parents' metaphases by using Chr8:61591397-61780768 (hg19) SureFISH probes (Agilent Technologies, Santa Clara, CA, USA) according to the manufacturer's protocol. This probe maps on chromosome 8 at the $C H D 7$ gene.

\section{Quantitative PCR}

Quantitative PCR (qPCR) analysis was performed as in [15]. The UCSC Genome Browser (Feb 2009 assembly; http://genome.ucsc.edu/) maps and sequence were used as references. Probe location was: RT1, chr8:6165396661654028; RT2, chr8:63979108-63979170. The sequences of all primers used are available from the authors.

\section{Genotyping}

Genotyping of polymorphic loci in the proband and his parents was performed by amplification of loci D8S260, D8S1718, and D8S1178 with primers labelled with fluorescent probes (ABI 6-Fam, Tet, and Hex), followed by analysis on ABI 3100 Genetic Analyzer (Applied Biosystems, Foster City, CA). Locus location was verified on the UCSC database.

\section{Consent}

Written informed consent was obtained from the patient for publication of this Case report and any accompanying images. A copy of the written consent is available for review by the Editor-in-Chief of this journal.

\section{Competing interests}

The authors declare that they have no competing interests.

\section{Authors' contributions}

$A B$ was responsible for the patient's clinical genetics examination; $S B$ performed FISH and chromosomal molecular assay; RG and MCB conceived and designed the molecular experiments and data analysis; PR and RQ ensured follow-up of the patient and contributed to the clinical description. MCB and AB co-wrote the paper. All authors read and approved the final manuscript.

\section{Acknowledgments}

We would like to gratefully acknowledge the family participating in this study.

\section{Author details}

${ }^{1}$ Medical Genetics Unit, Maternal and Child health Department, ASL of Imola, Imola, Italy. ${ }^{2}$ Cytogenetics Laboratory, Scientific Institute, IRCCS Eugenio Medea, Bosisio Parini, Via Don Luigi Monza, 20, 23842 Bosisio Parini(LC), Italy. ${ }^{3}$ Child and Adolescent Neuropsychiatric Unit, Mental Health and Pathological Dependencies Department, ASL of Ravenna, Ravenna, Italy. ${ }^{4}$ Pediatric Unit, Maternal and Child health Department, ASL of Ravenna, Ravenna, Italy. ${ }^{5}$ Molecular Biology Laboratory, Scientific Institute, IRCCS Eugenio Medea, Bosisio Parini, Lecco, Italy.
Received: 28 August 2013 Accepted: 7 October 2013

Published: 8 November 2013

\section{References}

1. Monfort S, Rosello M, Orellana C, Oltra S, Blesa D, Kok K, Ferrer I, Cigudosa JC, Martinez F: Detection of known and novel genomic rearrangements by array based comparative genomic hybridisation: deletion of ZNF533 and duplication of CHARGE syndrome genes. J Med Genet 2008, 45:432-437.

2. Lehman AM, Friedman JM, Chai D, Zahir FR, Marra MA, Prisman L, Tsang E, Eydoux P, Armstrong L: A characteristic syndrome associated with microduplication of 8q12, inclusive of CHD7. Eur J Med Genet 2009, 52:436-439.

3. Amouroux C, Vincent M, Blanchet P, Puechberty J, Schneider A, Chaze AM, Girard M, Tournaire M, Jorgensen C, Morin D, Sarda P, Lefort G, Genevieve D: Duplication 8q12: confirmation of a novel recognizable phenotype with duane retraction syndrome and developmental delay. Eur J Hum Genet 2012, 20:580-583.

4. Luo H, Xie L, Wang SZ, Chen JL, Huang C, Wang J, Yang JF, Zhang WZ, Yang YF, Tan ZP: Duplication of 8q12 encompassing CHD7 is associated with a distinct phenotype but without duane anomaly. Eur J Med Genet 2012, 55:646-649.

5. Pfaffenbach D, Cross H, Kearns T: Congenital anomalies in Duane's retraction syndrome. Arch Ophthalmol 1972, 88:635-639.

6. Anwar S, Bradshaw SK, Vivian AJ: Ophthalmic manifestations of trisomy 8 mosaic syndrome. Ophthalmic Genet 1998, 19:81-86.

7. Connell BJ, Wilkinson RM, Barbour JM, Scotter LW, Poulsen JL, Wirth MG, Essex RW, Savarirayan R, Mackey DA: Are Duane syndrome and infantile esotropia allelic? Ophthalmic Genet 2004, 25:189-198.

8. Vincent C, Kalatzis V, Compain S, Levilliers J, Slim R, Graia F, Pereira ML, Nivelon A, Croquette MF, Lacombe D, et al: A proposed new contiguous gene syndrome on $8 \mathrm{q}$ consists of Branchio-Oto-Renal (BOR) syndrome, Duane syndrome, a dominant form of hydrocephalus and trapeze aplasia; implications for the mapping of the BOR gene. Hum Mol Genet 1994, 3:1859-1866.

9. Calabrese G, Stuppia L, Morizio E, Franchi PG, Pompetti F, Mingarelli R, Marsilio T, Rocchi M, Gallenga PE, Palka G, Dallapiccola B: Detection of an insertion deletion of region 8q13-q21.2 in a patient with Duane syndrome: implications for mapping and cloning a Duane gene. Eur $J$ Hum Genet 1998, 6:187-193.

10. Pizzuti A, Calabrese G, Bozzali M, Telvi L, Morizio E, Guida V, Gatta V, Stuppia $L$, Ion A, Palka G, Dallapiccola B: A peptidase gene in chromosome $8 q$ is disrupted by a balanced translocation in a duane syndrome patient. Invest Ophthalmol Vis Sci 2002, 43:3609-3612.

11. Türkmen S, Guo G, Garshasbi M, Hoffmann K, Alshalah AJ, et al: CA8 mutations cause a novel syndrome characterized by ataxia and mild mental retardation with predisposition to quadrupedal gait. PLoS Genet 2009, 5:e1000487.

12. Verloes A: Updated diagnostic criteria for charge syndrome: a proposal. Am J Med Genet 2005, 133A:306-308.

13. Yüksel D, de Orban Xivry JJ, Lefèvre P: Review of the major findings about Duane retraction syndrome (DRS) leading to an updated form of classification. Vision Res 2010, 50:2334-2347.

14. Lyons PJ, Ma L, Baker R, Fricker LD: Carboxypeptidase A6 in zebrafish development and implications for Vlth cranial nerve path finding. PLOS ONE 2010, 5:e12967.

15. Novara F, Beri S, Giorda R, Ortibus E, Nageshappa S, Darra F, Dalla Bernardina B, Zuffardi O, Van Esch H: Refining the phenotype associated with MEF2C haploinsufficiency. Clin Genet 2010, 78:471-477.

doi:10.1186/1755-8166-6-49

Cite this article as: Baroncini et al:: $8 \mathrm{q} 12$ microduplication including CHD7: clinical report on a new patient with Duane retraction syndrome type 3. Molecular Cytogenetics 2013 6:49. 